\title{
Um testemunho de inéditas modalidades de inculturação ante litteram: a ação missionária dos jesuítas na China da Dinastia Ming nas Cartas do Pe. Matteo Ricci
}

\author{
Piero CECCUCCI \\ Xitai, ${ }^{2}$ depois de ter efetuado uma difícil \\ viagem de $80.000 l i^{3}$ para o Oriente, veio \\ à China para fazer amigos. Quanto mais \\ profundo é o conhecimento que ele tem \\ das doutrinas e da amizade, tanto mais sente \\ a necessidade de procurar amigos e tanto \\ mais de mantê-los.
}

1 Docente de Língua e Literatura Portuguesa e Brasileira na Universidade de Florença. Tem uma produção científica rica e diversificada com mais de 110 títulos, que compreende livros, ensaios, artigos, etc. e de que se podem salientar os trabalhos sobre Cesário Verde, José Saramago, Fernando Pessoa, a poesia portuguesa de hoje (Ana Hatherly, Sophia de Mello Breyner Andresen) e os trabalhos sobre Clarice Lispector e Jorge Amado, como assim sobre a acção missionária dos Jesuítas no Brasil, na China, etc. Traduziu para o italiano, com um grande êxito editorial, O Livro do desassossego e sempre de Pessoa, em dois volumes, a poesia orto-eteronima; piero.ceccucci@unifi.it

2 Li Xitai é o nome honorífico com que os chineses chamavam ao Matteo Ricci. Xitai quer dizer "Mestre do grande Ocidente".

3 O li é uma unidade de medida de distância, que corresponde a uns 500 metros. 


\begin{abstract}
$[\ldots]$
Eu, Yingjing, tão pouco capaz, em jovem estava mergulhado nos livros: não tive tempo para viajar à procura de amigos [...]. Ao ver que Xitai passou montes e atravessou mares para fazer amigos, sinto-me tão envergonhado! Então refleti sobre o seu ensaio e cada vez mais convenci-me de que mentalidade e doutrina do Oriente e do Ocidente são idênticas.
\end{abstract} (Feng Yingjing $\left.{ }^{4}\right)$

Após um século de viagens e descobrimentos portugueses, que "abriram o mundo ao mundo", e de uma sucessão rapidíssima de encontros, "por mares nunca de antes navegados" CAMÕES, 1972), com universos completamente desconhecidos, mas espantosos pelas suas belezas naturais exóticas e artísticas, entre os quais in primis o da China, propaga-se na comunidade eclesial católica do século XVI, com uma humanitas e pietas inéditas e exemplares, o debate sobre a função da criação e, por conseguinte, sobre o mistério da salvação. De resto, o extraordinário cenário do universo humano e natural das Índias, com a China e oJapão como ponto de chegada, que de forma inesperada, mas providencial, se ia então abrindo à evangelização, não deixava dúvidas sobre a necessidade da acção missionária de salvação de todos os homens, vistos como filhos de Deus.

Como corolário desse processo, era justamente a Companhia de Jesus que maior impulso dava ao debate e adequava a

\footnotetext{
4 Feng Yingjing (1555-1606), "letrado", amigo de Matteo Ricci, mandou imprimir em Pequim no ano de 1601 o Tratado da amizade, inserindo nele a 9 de fevereiro de $1601 \mathrm{um}$ seu prefácio, de que foi tirada a epígrafe, acima citada.
} 
sua prática evangelizadora a essas concepções, com um projecto missionário realmente inovador.

$$
* * *
$$

Como sabemos, a Companhia de Jesus constituíra-se formalmente em 1540 com a aprovação da Regra mediante a bula Regimini Militantis Ecclesiae, emanada pelo Pontífice Paulo III, a 27 de setembro do mesmo ano. Já no mês de abril de 1541, a pedido do rei de Portugal, D. João III, os primeiros Jesuítas guiados pelo Padre Francisco Xavier embarcaram para as Índias, onde só chegaram em maio do ano seguinte, devido a numerosas tempestades.

Os jesuítas, enquanto neófitos de uma ordem há pouco formada, eram verdadeiramente animados por uma fé extraordinária e apaixonada, que se revelava e manifestava de imediato através de uma atividade incansável de proselitismo e de evangelização, defendendo e propagando o Catolicismo no mundo, mas mantendo as tradições culturais autóctones. No Oriente, Francisco Xavier obtinha resultados surpreendentes graças à prodigiosa intensidade e novidade metodológica da sua acção missionária.

Isto vem explicar o extraordinário fenómeno da rápida difusão da Companhia em terras de Oriente, sustentado por um fluxo abundante e contínuo de jovens missionários cheios de entusiasmo. Foi um movimento que haveria de se prolongar ao longo do tempo, ao ponto de, um século mais tarde, o historiador italiano da ordem, Padre Daniello Bartoli (1608-1685) escrever: "Se si mandassero alle Índie quanti ne han desiderio, scemerebbe, si può dire, per metà la Compagnia in Europa" (BARTOLI, 
1825, p. 39) . Com efeito, quer antes, quer depois da "Grande Missão" de 1574 - durante a qual quarenta e um Jesuítas embarcaram para as Índias com o Padre Visitador Alessandro Valignano - segundo o Catálogo dos Padres e dos Irmãos que foram enviados para as Índias por ordem de cad'ano, entre 1541 e 1600, partiram 427 missionários da regra de Santo Inácio. Esses empenhavam-se com todas as suas energias na concretização da sua missão, que se baseava não no aniquilamento das culturas pré-existentes com que entravam em contacto, mas, num processo ante litteram de inculturação - cujo conceito filosófico-religioso analisaremos daqui a pouco - mas na recuperação e utilização, se não in toto pelo menos em parte, de elementos que podiam ser plasmados de forma a neles inserirem a palavra evangélica e a fé cristã.

De resto, para os jesuítas era quase um desafio e, como tal, aceitavam-no, conhecendo plenamente a tarefa que os esperava. Aliás, tinham a convicção - que de resto constituía a trave mestra da sua performance pedagógico-missionária -, de que só através de uma postura verdadeiramente respeitadora de modelos comportamentais ancestrais, poderiam suscitar o interesse junto de povos evoluídos quer em termos civilacionais quer em termos de riqueza de tradições religiosas. Tratava-se de uma performance que se realizava de modo muito coerente e claro em todas as terras do Oriente, sobretudo na China, cuja organização político-social e económica, e nível civilizacional alcançados eram superiores aos de todos os outros Estados. Nesse sentido, Serafim Leite, o grande historiador da acção missionária jesuita no Brasil, parece glosar:

5 "Se se mandassem para as Índias todos os que nos apresentam pedido, a Companhia ficaria com menos de metade dos seus efectivos na Europa" (Bartoli, 1825, p. 39). Su questo argomento si veda anche Gian Carlo Roscioni (2001). 
Ordem nova, protótipo das Ordens religiosas modernas, fundada com o fim determinado de propunhar, na Europa, pela unificação do espírito cristão e latino, in quavis mundi plaga, onde se travassem batalhas por Deus [e pela Igreja Católica, s.n.r.] os Jesuitas, sobretudo [...], logo se assinalaram em todas as regiões, onde flutuasse a bandeira das Quinas, como senhora e hospede de honra. No Oriente S. Francisco Xavier assombrou o Mundo com as suas maravilhas. (Leite, 1938, X)

Assim, o padre jesuíta, Matteo Ricci (nascido na cidade de Macerata em 1552 e falecido em Pequim em 1610), num atento processo de inculturação, prudente e decisivo, fazia de tudo para entrar imediatamente em sintonia, por um lado com a metodologia evangelizadora dos inacianos, por outro lado com a mentalidade dos nativos, chegando até a abdicar dos seus trajes de estrangeiro, muito mal vistos pelos chineses, e edificando casas e igrejas de acordo com a estrutura arquitectónica e as cores do urbanismo chinês, abandonando o estilo europeu e fazendo com que a missão, como lugar real de residência, passasse o mais despercebida possível. Como ele recorda:

E porque ja tinhamos determinado de deixar os nomens de bonzos, que entre os Chines he tido em tão vil e baixo estado, e tomar nome de letrados e pera isto conforme aa licença que nos tinha deixado o padre visitador, fizemos creser as barbas e o cabelo ate orelha, e iuntamente haviamos de usar de um vestido particular, que os letrados usã no tempo das visitas e não do que primeiro usavamos de bonzos. (RICGI, 2001, p. 217) 
As medidas adoptadas, que aos nossos olhos poderão parecer precauções tácticas, correspondiam verdadeiramente a uma específica estratégia de pensamento, ou se quisermos, a uma efectiva preocupação ideológica; porque era real a necessidade, mas também o sentimento, com vista à evangelização, de uma adequação aos modelos culturais locais, aceitando-os e deles se apropriando nas modalidades e nos comportamentos da vida quotidiana. De resto, os missionários jesuítas, graças à sua longa e orientada educação recebida nos colégios, eram estimulados a plasmar uma sua própria forma mentis das categorias de pensamento específico que, harmonizando-se no conjunto dos seus confrades, encontravam a sua justifcação teórica e comportamental nos textos fundadores da Companhia, como as Constituições e os Exercícios Espirituais, onde o tema da missão surge, sem sombra de dúvida, como o que melhor caracteriza a identidade jesuíta.

Assim, os missionários que operavam no Império Celeste, através de performances mutáveis e adaptadas aos acontecimentos e às circunstâncias sociais, iam ultrapassando com êxito desconfianças e oposições. A esse propósito, como sublinha Horácio Peixoto de Araújo num seu excelente estudo "os efeitos de tal mudança não se fariam esperar, manifestando-se, especialmente, ao nivel da facilitação das relações com os mandarins e de um acrécimo de credibilidade junto das populações" (ARAújo, 2000, p. 109).

Era, sem dúvida alguma, a atitude mais correcta e certeira no processo de inculturação que, favorecendo a abertura no sentido de um intercâmbio cultural, acabaria por facilitar a entrada dos Padres nas mais altas instâncias do poder chinês e fornecer um decisivo impulso à evangelização. Através da actividade missionária, assim concebida e posta em prática, a Companhia 
não só se abria para o mundo, glorificando Deus, como também implementava uma nova forma de monaquismo, abandonando a clausura para modelar e impor uma inédita "ascese intramundana", de um itinerarium a Deum ${ }^{6}$ individual no apostolado entre as gentes do mundo.

Por outro lado, na China, o nível de civilização era decididamente superior ao de qualquer outro território extraeuropeu. Se abdicarmos do pressuposto que leva a associar o nível de civilização com o desenvolvimento e o progresso da ciência e da técnica, apanágio da Europa ocidental, instrumento de poder e colonialismo, teremos forçosamente de reconhecer que na China de então, no pensamento e nas artes, bem como na organização e no exercício do poder, se tinham alcançado níveis de excelência, até mesmo em relação ao modelo europeu. E isso aparece nitidamente desde as primeiras reflexões sobre o Império de Meio que o já recordado Pe. Visitador Alessandro Valignano fez, quando se encontrou pela primeira vez, em setembro de 1578, em Macau:

El reyno de la China es tan diferente de todos los demás reynos y naciones que hay en todo este Oriente, assí en la qualidad de la gente y sus costumbres, como en la qualidad y fertilidad de la tierra, que no tiene quasi nenguna semejança con los otros, mas a todos excede; y es la cosa más principal y más rica que hay en todo el Oriente. [...] Es la más pacifica y bien governada tierra que hay en lo descubierto; y es mucho de meravillar,

6 A leitura dos textos fundadores da Companhia de Jesus permite-nos conhecer não só as origens e as intenções da missão, mas também aceder à própria essência das categorias jesuítas. A missão não é apenas um meio para ampliar o reino de Deus, mas uma modalidade de salvação pessoal. 
specialmente siendo de gentiles, que no tienen luz de la verdad ni de la doctrina de Dios, que es la que enseña el verdadero modo de govierno. (Valignano, 1944, p. 214-215)

O Padre Visitador tinha-se apercebido logo da enorme importância estratégica da China, embora não subestimasse as graves dificuldades e os riscos reais que os missionários corriam ao entrar na terra dos chineses. Todavia, tendo em conta as extraordinárias potencialidades que se abriam à evangelização, tinha solicitado os Padres Michele Ruggeri e Matteo Ricci, que na altura se encontravam em Goa, para que se transferissem para Macau e se dedicassem ao estudo da língua e da cultura chinesa, em vista à entrada naquele Pais.

Além disso, os próprios padres missionários no dito processo de inculturaçaõ, tanto cuidadoso quanto decisivo, fizeram tudo para entrarem logo nos modelos de comportamento dos nativos.

De fato, no Império Celeste, foi o Matteo Ricci que, exemplarmente, ensinou os colegas para agirem com a prudentia et pietas do "bom pastor", do padre amorável e do irmão diligente. Sobretudo, ciente que esse processo de evangelização apesar de o mesmo assentar numa relação de reciprocidade, o Ricci monstrou-se, desde os primeiros contactos, atento e respeitoso em relação às tradições e aos modelos culturais enraizados e, certamente, não "bárbaros", que nada tinham a invejar aos europeus, pondo a tónica do projecto de evangelização nos mecanismos de composição harmoniosa de um encontro de culturas capazes de dialogarem entre si e de se abrirem a uma influência recíproca e profícua.

Ao mesmo tempo, porém, soube tirar proveito dos seus conhecimentos tecnológicos e científicos superiores, que des- 
pertavam vivo interesse junto das autoridades locais e centrais. Especialmente no que se referia às ciências matemáticas e astronómicas, bem como a alguns instrumentos, de que o nosso grande apóstolo da China era profundo conhecedor, ${ }^{7}$ graças à óptima educação que recebera em Roma, adquirindo assim grande estima e consideração, junto dos mandarins e "letrados" chineses e na própria corte imperial de Pequim, não só pelos conhecimentos humanísticos e científicos que mostrava possuir, mas ainda pela capacidade de construir esferas metálicas, quadrantes solares, prismas, relógios, canóculos (a elaboração do seu primeiro Mapamundi é de finais de 1584), que depois doava às autoridades ou a pessoas influentes no entourage político-administrativo local.

De fato, durante a sua formação humanística no Colegio Romano, que podemos equiparar aos nossos Institutos Superiores Universitários, ${ }^{8}$ teve a grande sorte de encontrar como professor o célebre matemático e astrónomo Cristoforo Clavio, autor do tratado In spheram Ioannis de Sacro Bosco Commentarius, 1570, conhecido simplesmente como Esphera e que foi também um dos artífices da reforma do Calendário Juliano, promulgada pelo papa Gregório XIII em 1582.

Entrar, portanto, no imaginário e na cultura compósita desse imenso país e, ao mesmo tempo, utilizar a sua superioridade tecnológica e científica, representava para o missionário maceratese a condição imprescindível para abrir uma brecha na

\footnotetext{
7 Lacouture (1991, p. 261).

8 Na verdade, adaptado ao modelo do Ateneu de Paris, o Colégio Romano foi outorgado pelo Papa Paulo IV como centro de estudos superiores no ano de 1556. Tinha nascido como "Escola de gramática, de humanidades e de doutrina cristã", em que podiam entrar os jovens "omnis conditionis", de todas as condições sociais, provindos de diversas nações europeias. Por isso foi titulado de "Collegium Universale - Omnium Nationum Seminarium". (Vd. Scartezzini, 2009, p. 38).
} 
postura dos Chineses, orgulhosamente conscientes do valor da própria civilização, com vista a um projecto missionário duradouro e profícuo.

Nisso emerge, de forma evidente, a extraordinária capacidade do jesuíta a adaptar-se e submeter-se - sendo ponto assente os fins da evangelização e os fundamentos da doutrina católica - às diferentes circunstâncias e situações quer espaciais quer temporais em que vinha a encontrar-se durante a prossecução da sua missão.

$$
\text { *** }
$$

Portanto, o ponto central da ação missionária no plano teórico e prático do Padre Matteo Ricci, que constitui aliás o próprio fundamento do seu sucesso em terras chinesas, baseia-se essencialmente numa abordagem empática, que ultrapassa - ainda que inconscientemente - qualquer processo de interculturação, com a milenária cultura de um povo, como ele mesmo defende, naturalmente predisposto ao bem. Trata-se, antes, visto e definido com a mais correta terminologia filosófico-antropológico-eclesial de hoje, de um original e acabado modelo de inculturação, segundo a codificada, afinal de contas, recente aceção formulada pelo Sínodo dos Bispos italianos em 1977 e formalizada pelo Papa João Paulo II.

Ultimamente reproposta pelo pontífice Bento XVI, a inculturação fundamenta-se, de facto, em formas de fecundo diálogo entre os povos, que em referência à ação missionária dos Jesuítas na China, encontra no Padre Matteo Ricci ${ }^{9}$ o pioneiro e

9 Recorde-se que, no quarto centenário da sua morte, a 10-11 maio de 2010, se celebrou, também na Universidade de Florença, a figura do célebre apóstolo da China, 
o testemunho mais incisivo e significativo do encontro paritário de culturas tão diferentes e tão distantes. Ele, de fato, emerge assim como personagem singular que soube realizar um inédito estilo de evangelização, através de uma metodologia científica e uma estratégia pastoral baseadas, por um lado, no respeito dos usos sãos do lugar e, por outro, na consciência que o verbo cristão podia ainda mais valorizá-los e completá-los, tirando dele, o próprio movimento missionário, de reflexo, alto enriquecimento espiritual e novo impulso; uma personagem, portanto, de elevada estatura moral e inteletual, cuja metodologia evangelizadora, tenazmente seguida e defendida, se plasmou como modelo de diálogo entre culturas, de respeito e de colaboração, de encontro e de profícuo, sugestivo intercâmbio entre dois mundos que se esforçavam por compreender-se.

O nosso jesuíta, de resto, encorajado também pelos antigos escritos filosóficos da tradição cultural dos "letrados" dos quais aflora, como extrema síntese de pensamento pedagógico-religioso, uma famosa máxima moral de K’ung fu tzu, conhecido no Ocidente com o nome de Confúcio, relatada num fragmento dos Lü jü (Diálogos) - que afirma: "Podemos aprender a ser sábios de três maneiras. A primeira é aprender a refletir e é a melhor. A segunda é a imitação, e é a mais fácil. A terceira é confiar na experiência, e é a mais dolorosa" - (o jesuíta, dizia eu) indica com o exemplo e com a palavra, sobretudo escrita, mas também com a sua postura metodológica, fruto de atento estudo e de experiência, aos seus confrades e à Instituição os percursos de sapiência confucianos que, apoiando-se na tradição cultural do

com um Congresso Internacional, com ampla repercussão cultural, intitulado "Quarto Centenário da Morte do Padre Matteo Ricci (1552-1610), do qual em 2012 saíram as respetivas Atas com a chancela da Sociedade Editora Dante Alighieri di Roma. 
Império de Meio, oportunamente recebidos e repropostos pelos evangelizadores, mediante a reflexão, o exemplo e a maturação humana, teriam contribuído para levar o homem chinês para o homem novo cristão. Deste modo, Li Madou (transliteração chinesa de Matteo Ricci) acabaria por se propor como importante testemunho e reconhecido protagonista de um fenómeno que, ontem como hoje, é central no Cristianismo e na obra de evangelização, e que encontrou a posteriori na inculturação, nas últimas décadas do século passado, como acima referido, uma acabada estruturação concetual. Esta, em termos antropológico-filosóficos em oposição à aculturação, entendida negativamente como modalidade de absorção e dissolução destrutiva das diversidades étnico-culturais dos vários povos, define-se nitidamente como

[...] abordagem missionária-pastoral-cultural que reconhece a diferenciação das culturas e escolhe encaixar nelas a semente do Evangelho de forma a, na base de uma mútua fecundação (entre semente e terreno fértil), se realize uma autêntica encarnação e regeneração benéfica do próprio Evangelho no novo contexto. (RAVASI, 2009, p. 27)

Essa escolha pastoral, teológica e cultural, sentida aliás como enriquecimento recíproco espiritual entre os diversos atores, encontrou no Papa João Paulo II, como acima recordado, o seu mais convicto defensor, ao ponto de, num discurso proferido no Quénia em 1980, afirmar: “A inculturação será realmente um reflexo da encarnação do Verbo, quando uma cultura, trasformada e regenerada pelo Evangelho, produz a partir da sua própria tradição expressões originais de vida, de celebração, de pensamento cristão" (Giovanni PaOlO II). 
A intervenção do Papa polaco foi determinante para recolocar no trilho da ortodoxia as várias diatribes sobre a ação missionária dos jesuítas na China - em primeiro lugar de Matteo Ricci -, não só confirmando o decreto de tolerância sobre os Ritos chineses de Pio XI ${ }^{10}$ e acabando com a chamada "Questão dos Ritos", ${ }^{11}$ que durante séculos tinham moldado a Igreja chinesa, mas reconhecendo mesmo a correção teológico-doutrinal da estratégia evangelizadora dos "inacianos".

A inculturação, enfim e como já dito, não pode ser redutivamente vista como tática missionária ou, no máximo, como estratégia pastoral, mas deve ser assumida como estrutural à evangelização, operada pelos Jesuítas, e à própria fé cristã, como sapientemente tinha compreendido e posto em prática, ante litteram, Matteo Ricci, com uma anticipação de quatrocentos anos, na formulação concetual de uma específica ação missionária. De facto, tornando-se chinês entre os chineses, ele conseguia, graças a uma fé intrépida e firme, naquela missão considerada impossível aos demais, abrir as portas do grande Império de Meio, fechado em si mesmo e hostil ao estrangeiro, avançando com convicção e prudência ao encontro com o outro, portador de uma mensagem de irmandade, de paz e de ascenção social e espiritual que viria a encaixar-se, vivificando-a, na tradição mais fecunda do pensamento confuciano, professado e seguido pelos "letrados".

10 Pio XI em 1939 tinha acabado com a "querelle" relativa aos ritos chineses, promulgando um decreto de tolerância, embora reconhecesse deles só o sentido social.

11 Recordamos aqui, incidentemente, que o Papa Clemente XI em 1704 tinha chegado ao ponto de promulgar um decreto de condenação dos ritos confucianos, tolerados pelos jesuitas, reforçado e agravado em 1715 com a bula Ex Illa Die, vindo proibir claramente, como não ortodoxa no plano teológico-doutrinal, a metodologia evangelizadora dos jesuitas e do próprio Ricci. 
Decerto ter-lhe-ão servido o conhecimento da língua e da escrita chinesa ${ }^{12}$, cujo estudo tinha iniciado imediatamnete após a sua chegada a Macau (1582), sabendo-as tornar suas para cruzar o diálogo paritário e construtivo com a doutrina confuciana, numa troca de saberes aberta e respeitosa. Não é por acaso nem sequer neutral que, neste sentido, ele se-autodefina um "confuciano ocidental" 13. Bastará, a esse propósito citar o Tratado da Amizade (1595) e as Vinte e cinco sentenças (1605), escritos por Matteo Ricci diretamente em língua chinesa, não tanto para conferir vestes orientais à mensagem evangélica, mas sobretudo para lhe dar maior profundidade comunicativa.

Mas, para compreendermos plenamente e melhor do nosso jesuíta a postura, o pensamento, as aspirações, mas também os improvisos temores e abatimentos, relacionados com os êxitos do seu incansável labor, não podemos não colocar em primeiríssimo plano, entre os seus escritos mais significativos, as Cartas - ainda que grande parte delas perdidas ou nunca chegadas ao destino, por causa dos inúmeros naufrágios das embarcações do tempo - hoje disponíveis num belo volume ${ }^{14}$, em que podemos encontrar, sob o signo da inculturação, as mais convictas teses de uma metodologia de evangelização esforçada e difícil, mas frutuosa e, sobretudo, precursora dos tempos.

Escreve a este respeito de Nanchang em 1595 ao Padre Duarte de Sande S.I.:

12 "Eixo da nova estrátegia era o domínio da língua do pais que o acolhia, para poder interagir sem necessidade de intérpretes e de ser capaz de estudiar as crenças religiosas, a cultura, as tradições, os ritos e os hábitos de vida, bem como as regras que regulavam as normais relações interpersonais". (Vd. RicCARdo Averini, p. 37).

13 Vd. Wang Suna e Filippo Mignini (2010, p. XIX).

14 Vd. nota 7 do presente capítulo. 
Como V.R. ve, himos muito cresendo no credito e no respeito com os Chinas; o qual he summamente necessario assi pera poder ter entrada com os grandes, como tambem pera que tenhão em estima nossa sancta ley e doutrina. Porque, posto que não seia de nossa profissão andar buscando honras, todavia nesta terra, onde a lei de Nosso Senhor não he conhecida e do credito e reputaçã que terão os pregadores desta sagrada doutrina depende, em hum certo modo, tam bem a reputação da mesma lei, he necessario quanto ao exterior que nos acomodemos com os costumes e modo de proceder dos Chinas. E bem se comessa a enxergar quanto isto emporta: porque ata agora com hirmos mais humildemente no esterior e sermos tidos por bonzos, fomos sempre tratados como gente baixa e de nenhum ser, nem numca podemos ter entrada com os mandarins e outras pessoas de conta; e agora com esta mudança que fizemos ja comesamos a ter entrada com todos e somos tratados delles com muita honra e cortezia: quanto mais que pera nos não fazer mal esta honra e credito, que agora comesamos a ter entre os Chinas, nos fez Nosso Senhor passar primeiro por doze anos continuos em Xauquin (Zaoqing) e em Xaucheo (Shaozhou) tantas desonras, abatimentos e afrontas e tantas perseguições. (Ricci, 2001, p. 264-265)

$$
* * *
$$

O volume em questão assumido por mim quase como repertório rico de acentos de inculturação, editado pela chancela 
da Quodlibet de Macerata (2001), ${ }^{15}$ terra do Ricci, recolhe um corpus de 54 cartas, mais uma, a quinquagésima quinta, datada de 12/11/1607 e endereçada ao Padre Gaspar Fernandes, provincial da Índia em Goa, colocada em apêndice. Esta, enfim, não é uma verdadeira carta, mas o resumo de uma passagem de uma missiva que não chegou ao destinatário.

Como é óbvio, para os fins hermenêuticos que me propus, não farei uma análise estilistico-estrutural das cartas, nem irei examinar as várias questões temáticas nelas desenvolvidas. Ater-me-ei exclusivamente ao argumento escolhido, o de apreender e pôr em evidência a metodologia evangelizadora de Ricci, como aflora dos textos e que, mostrando tirar proveito dos ensinamentos recebidos nos anos de estudo e de formação no Colégio Romano, acima recordado ${ }^{16}$, de facto, "como a experiencia é a que melhor ensina" (Gouves, 2001, p. 100), adota, no encontro com o outro, uma originalíssima estratégia de diálogo e generosa atenção para com a cultura milenária com a qual entra em contato. Inaugura, afinal, formas de inculturação eficazes e sobretudo personalíssimas; audazes para o tempo, tanto que, como acima indicado, pelas outras ordens (domenicanos e franciscanos) - entrados na China no século XVII ${ }^{17}$ - depois da sua morte - talvez também com uma ponta de disfarçada inveja, consideradas não

15 Na verdade, o texto das cartas do nosso missionário foi extraído, salvo pouquíssimas variantes, do segundo volume das Opere storiche del Pe. Matteo Ricci S.I., editadas com organização do Comité para as honras nacionais com prolegómenos, notas e quadros do Padre Pietro Tacchi Venturi S.I., Macerata, Stab. Tip.Giorgetti, 1911-1913.

16 Vd. nota 10 do presente texto.

17 Os primeiros missionários dominicanos entraram na China em 1631, enquanto os franciscanos - se exceptuarmos o periódo da sua presênça na China de 1294 a 1368, em que se salienta a figura de frey Giovanni da Montecorvino (1247-1328), durante a Dinastia Yuan - chegaram ao Celeste Império da Dinastia Ming em 1633. 
completamente ortodoxas, criticadas por muitos e longos anos, provocaram a inopinada e ruinosa condenação do método ricciano por parte do Santo Ofício romano em 1704. A consequência foi que, alguns anos mais tarde, o imperador Kangxi que, embora em 1692 tivesse promulgado um decreto de tolerância para os missionários ocidentais, irritado pelo comportamento arrogante dos delegados pontifícios cada vez mais irreverentes perante ele, começou a tornar-se rígido nas suas posições. Instaurou-se assim de novo um clima de incomunicabilidade extremamente aceso entre a China e a Igreja Católica, que induziu em 1724 o Imperador Yongzheng, sucessor de Kangxi, a emanar o edital de expulsão de todos os "bárbaros" europeus. Fecharam-se desse modo, definitivamente, aos missionários ocidentais, as portas que Ricci, com o seu saber, o seu amor e a sua ductilidade performativa, tinha conseguido abrir. A desconfiança e os medos perante o estranho-estrangeiro voltaram a erguer barreiras entre os dois mundos, com alternadas oscilações até hoje.

E, no entanto, como sublinhámos acima várias vezes, as Cartas abriam um amplo campo à discussão, quer interior quer exterior da própria Companhia, constituindo um precioso testemunho de uma sagaz ação missionária, que Ricci, com o seu saber e a sua dedicação de pastor, tinha positivamente sortido efeito de instaurar com o universo chinês, no diálogo e na recíproca confrontação, vencendo a desconfiança de governadores e mandarins, até obter a benevolência pessoal do próprio Imperador, que o tinha chamado à corte, embora sem o admitir nunca na sua presença nem lhe falando diretamente.

Está fora de questão que tenham sido o seu forte sentimento religioso, a sua fé e o amor a Deus e ao próximo a induzir o jesuíta a uma particular atenção com este povoadíssimo e sempre amado reino, onde com imensos sacrifícios ia recolhendo riquís- 
simos frutos espirituais de salvação, absorvendo-lhe a língua, cultura e estilo de vida. Escreve assim de Zhaoqing em 10/1 1/1585:

Como homem, que aqui me parece que irei acabar os poucos dias que Deus me concederá de vida, vou-me acomodando e afeiçoando à terra quanto posso, e cada dia vou podendo mais, porque já falo correntemente a língua e comecei pregar aos cristãos na nossa igreja, e daqui em diante temos de abrir a porta também a alguns gentis que o desejem. De igual modo fiz com ao ler e escrever as suas letras, que são alguns milhares; porque vou intendendo muitos livros sozinho et todos com uma ajuda qualquer. (RICGI, 2001, p. 109)

As Cartas ricciane propõem-se, portanto, como precioso documento emblemático da fenomenologia do encontro e do diálogo e como texto eloquente de análise de suasiva metodologia comunicativa, capaz de derrubar barreieras de medos ancestrais, de desconfianças e de incomunicabilidade.

Com efeito, eles desenham uma pessoal e natural inclinação de Ricci para estabelecer relações de atenção e de afeto com o estrangeiro, até à abnegação e anulação do seu próprio eu, renunciando a grande parte dos sonhos, com os quais vem sendo construída a identidade pessoal. Decidindo "fazer-se enteiramente China", para comunicar com este "outro mundo", com os homens "de diversas nações", ele não hesita em despojar-se de todos os sinais exteriores da sua identidade de filho da Europa (língua, alimentos, roupas, costumes, formas de relação social), chegando a ocultar até muitos signos e símbolos, que considera estritamente não essenciais, da sua fé religiosa. 
Quase todas as cartas que compõem o volume descrevem, mesmo a intervalos irregulares, por causa da muito precária circulação das missivas, um modo de ser, de se colocar e de se propor do missionário que, por índole ou consciente escolha, desenvolve e aperfeiçoa um método de evangelização, levando, com a máxima, infinita humildade, até ao extremo do humano possível, a capacidade de se negar - excetuando os princípios da fé - como homem religioso imbuído de doutrina ocidental, pronto a abrir-se aos saberes do outro, aprendendo-lhes a língua e lendo e estudando os livros dos Letrados confucianos.

A 8 de março de 1608, escreve ao Preposto General da Companhia, Pe. Claudio Acquaviva:

Por esta causa, faço tudo o que puder para que todos os nossos Padres estudem muito bem os livros da China e procurem saber compor; porque na verdade, coisa que não se crê facilmente, faz-se mais na China com os livros do que com palavras [...] e deve-se proceder nesta via com muita maturidade para ser esta gente sábia nas coisas do mundo, alertada e suspeitosa dos forasteiros; acima de tudo, deve-se considerar bem os sujeitos que nestes principíos se enviam, que sejam prudentes e de bons estudos, porque tratamos com gente exercitada nos seus livros, e não facilmente lhes poderiamos vender chumbo por prata. (RicCI, 2001, p. 470-471)

Numa outra carta, alguns meses depois, a 23 de agosto de 1608, pontualiza desse modo o seu pensamento ao Pe. Fabio de Fabii que se encontra em Roma: 
Com tudo isto, pregamos aqui continuamente a nossa santa lei com palavras e com livros, e está entre os letrados em muito boa reputação, porque tratamos aqui todos com muito respeito, tanto grandes como pequenos; e de forma a que nenhum se queixe de nós, todo o dia estou na sala recebendo gente que nos vem visitar, e depois disto vou-lhes retribuir a visita, às vezes, oito ou dez mihas de distância. (Ricci, 2001, p. 501)

Todavia, a carta mais importante, entre as que nos chegaram, referentes à metodologia ricciana é a que foi enviada, a 15 de fevereiro de 1609, ao Viceprovinciale da Compagnia, Pe. Francesco Pasio, que constitui, um ano antes da morte do autor, uma espécie de revisitação testamentária de toda uma vida, passada ao serviço de Deus e da Igreja, levando o dom da palavra evangélica à amadíssima "nação" chinesa.

Ao mesmo tempo, ela configura-se também como um legado espiritual e operativo, para os seus sucessores, para que não abandonem o seu exemplo e a sua metodologia de apostolado, propondo-os aos confrades, aos fiéis e ao mundo chinês como sinal e convite à continuidade, para que:

[...] quando morrermos nós que fomos os primeiros, e quando também morrer este rei, a mesma coisa deve ter um seguimento com a divina graça. E assim o meu parecer agora seria que, como nesta corte estamos com tanto crédito e com estima não só daqueles que estão fora da corte, mas também dos mandarins da corte, e embora seja falso que o rei nos queira muito bem e que às vezes fala connosco, devemos nós aproveitar para pôr mais padres em diversas partes da China, para que, 
quando faltasse aos nossos este apoio do favor que se dá a eles da nossa parte, mantidos pelo erário do rei, ficasse a China cheia dos nossos confrades em segurança sem medo de serem expulsos. [...] O risco de qualquer edital do rei contra nós só existe em duas coisas: uma é manter relações com os forasteiros, e fazer saber fora do reino que somos mantidos e damos e temos informações; a outra é o pregar a lei nova na China. A este segundo nós não podemos obviar, uma vez que é esta a nossa finalidade, se não confiar na divina providência, [...] e da nossa parte fazer esta missão prudentemente e com discrição e com bons livros e boas argumentações, demonstrando aos letrados a verdade da nossa doutrina [...]. E sobretuto neste começo procurar bons cristãos que muita multidão, e se for possível alguns letrados de alto grau e mandarins, que pudessem com a sua autoridade, serenar aqueles que tivessem medo desta novidade. (RICCI, 2001, p. 513-514)

Enfim, continuando, ele resume, teoricamente, com extrema síntese e lucidez, em oito pontos, os elementos fundadores daquela estratégia evangelizadora, que valerá a pena di referir como conclusão do presente trabalho. Com efeito, segundo as convicções metodológicas missionárias de Ricci, nascidas da experiência de trinta anos de obra feita no Império de Meio, a difusão do cristianismo foi-se articulando segundo as seguintes prioridades operativas, que nós, hoje em dia, reconhecemos constituir a própria essência da inculturação.

Realmente, ele diz:

O primeiro motivo [a ter em consideração, n.d.r.] é ver o princípio e o progresso desta missão como muito mi- 
lagroso, e semelhante ao que são próprios das coisas divinas; [...] visto que já vamos contando os cristãos feitos aos milhares [...] e somos estimados não só como homens muito virtuosos, mas também por letrados e de muito valor $[\ldots]$.

O segundo, uma vez que neste reino são muito apreciadas as letras e, consequentemente, as ciências e as argumentações fundadas na razão. [...] E por isto parece ser fácil convencer os principais do reino sobre as coisas da nossa santa fé confirmadas com tanta evidência de raciocínio, e obtendo o consenso das pessoas mais importantes que existem entre elas, será fácil converter todos os demais. [...]

O terceiro, que segue este, é a facilidade que temos de divulgar a nossa santa religião cristã com livros que entram por toda a parte sem impedimento; e assim facilmente se divulgam $[\ldots]$ as coisas mais consideradamente e com mais exatidão do que aquilo que se pode dizer verbalmente.

Quarto: são os chineses de belo engenho natural e aguto, $[\ldots]$ que surpreende todo este Oriente. Por isso, se lhes pudéssemos ensinar as nossas ciências [...] por meio delas levá-los-emos facilmente à nossa santa lei. Quinto: são também inclinados para a piedade, ainda que a outros possa parecer o contrário, porque fui descobrindo isto pouco a pouco. [...] E, examinando bem todos os seus livros, encontraremos neles pouquíssimas coisas contra o lume da razão e muitíssimas conformes a ela.

Sexto: têm bastante facilidade em conservar-se cristãos, os que se podem fazer por causa da grande paz que 
ordinariamente há neste reino [...] E é certo que se a este se pudesse converter o rei e a sua casa real, seraiam eles mesmos a procurar que todos se fizessem cristãos [...], porque se fossem os Chineses cristãos, nunca mais existiriam entre eles as revoltas e as perturbações dos Estados que existem por vezes e que sempre se temem. Sétimo: com isto e com o modo que usámos para tratar com pessoas muito importantes e segundo as suas maneiras corteses, todos os nossos já ganharam o nome de doutos e santos, e creio que devemos conservar isto até o fim; porque, aliás vão aqui muito bons missionários e todos teólogos, não houve ninguém até agora que não atenda mais do que mediocremente às letras da China, uma vez que saber as nossas sem saber as deles não serve de nada; e V.R. verá bem quanto importa este punto nestes inícios. Por mim considero-o mais do que ter feito mais dez mil cristãos, para ser este meu agir favorável e necessário para a conversão universal de todo o reino. Oitavo: com este ponto, quero sublinhar o apoio que temos dos livros dos leitrados da China para as coisas da nossa fé. [...] e como, por meio disto, muitos deles se fizeram cristãos e dão sinais manifestos de ser claramente bons cristãos. (RICCI, 2001, p. 516-520)

A coisa que parece incontrovertível desta longa citação é que o método missionário de Ricci é um cruzar de tantas estratégias e é difícil captar-lhe o nexo unificante sem primeiro enovelar os muitos fios que o compõem, analisando-o um por um: a chegada a Pequim, a permissão imperial, o apostolado através da ciência, o acomodamento, a distinção entre catecismo e doutrina cristã, a diferença entre apostolado direto e indireto, 
a admissão na Companhia dos nativos, o apostolado através dos livros, a frequência de letrados e funcionários.

Todos, porém, tomados no seu conjunto, reconduzem a um único conceito, explicitado no termo "acomodamento"18, que é o elemento caracterizador e central da inculturação. Com efeito, o método do acomodamento, seguido na sua atividade missionária, mergulha as suas raízes no pensamento teologico-pedagogico de S. Tomás de Aquino e de Erasmo de Roterdão. Acomodamento, portanto, não quer dizer, ao enfrentar complexas questões culturais e religiosas, ceder perante as razões do outro renunciando às próprias convicções, mas - no nosso caso específico - suma disponibilidade e vivo espírito de caridade a encontrar um elemento de síntese entre duas diferentes tendências de pensamento, a confuciana e a cristã, que, salvaguardando a essência irrenunciável das questões da fé e da verdade revelada, permita abrir-se à escuta das razões do interlocutor.

No fundo, em toda a ação missionária de Ricci há qualquer coisa de semelhante entre o seu método de evangelização e a catequese dos primeiros séculos do cristianismo, quando ela previa a atenção ao bom que provinha do mundo antigo e a introdução gradual aos mistérios da fé. Gradualidade e ductilidade parecem a estrela polar da ação missionária do nosso jesuíta, que

18 Segundo um modelo proposto pelo psicólogo suíço Jean Piaget e largamente aceitado, existiriam os dois processos de assimilação e de acomodamento, através dos quais os esquemas mentais são enriquecidos mediante a incorporação dos contributos provenientes do ambiente. Estes dois mecanismos são complementares e asseguram a manutenção do equilíbrio entre continuidade e mudança. Por extensão, porém, no sentido político-social e filosófico-antropológico,

a adaptação significa tomar consciência de uma nova realidade, para nela adaptar as suas categorias filosofico-antropológico-religiosas, segundo o pensamento tomista e erasmiano, que constituía um dos fundamentos pedagógicos, ensinados no Colégio Romano dos Jesuítas. 
tem - só para dar um exemplo - com o apóstolo Paulo de Tarso - e o confronto não deve parecer irreverente - surpreendentes pontos de contato e de convergência estratégica, na adaptação do método às situações e à experiência.

Como glossa iluminante, a tudo quanto disse, chegam, como conclusão, as palavras de alta autoridade do Papa Bento XVI, que acabam por encerrar com sapiência e síntese eloquente o presente trabalho:

Não obstante as dificuldades e as incompreensões que encontrou, o Padre Matteo Ricci quis manter-se fiel até à morte, a esta modalidade de evangelização, atuando uma metodologia científica e uma estratégia pastoral baseadas, por um lado, no respeito dos hábitos sãos do lugar, [...] e, por outro, na consciência que a Revelação podia ainda mais valorizá-las e completá-las. E foi mesmo a partir destas convicções que ele, como já o tinham feito os Padres da Igreja no encontro do Evangelho com a cultura greco-romana, imprimiu o seu trabalho sagaz de inculturação do Cristianismo na China, procurando um entendimento constante com os doutos daquele país. (BENEDETTO XVI, 2012, p. 16)

\section{Bibliografia}

Andreotti, Giulio. Un gesuita in Cina (1552-1610). Milano: Rizzoli, 2001.

Catto, Michela; Mongini, Guido. Missioni e globalizzazioni:

L'adattamento come identità della Compagnia di Gesù. In: 
Evangelizzazione e globalizzazione. Le missioni gesuitiche nell'età moderna tra storia e storiografia. Roma: Società editrice Dante Alighieri, 2010. p. 1-15.

D'Elia, Pasquale M. Storia dell'introduzione del Cristianesimo in Cina. In: Fonti Ricciane: documenti originali concernenti Matteo Ricci e la storia delle prime relazioni tra l'Europa e la Cina (1579-1615). Roma: La libreria dello Stato, 1942-1949. 3 voll. Edite sotto il patrocinio della Reale Accademia d'Italia (Edizione nazionale delle opere edite e inedite di Matteo Ricci).

Feng, Yingjing. Prefazione per la stampa dell'Amicizia [1601]. In: Rica, Matteo. Dell'amicizia. Macerata: Quodlibet, 2005.

Fontana, Michela. Matteo Ricci, un gesuita alla corte dei Ming. Milano: Mondadori, 2005.

MieLI, Paolo. Il Vangelo e Confucio: un incontro mancato. Corriere della Sera, Milano, 24 luglio 2012.

Mignini, Filippo. Matteo Ricci. Il chiosco delle fenici. Ancona: Il Lavoro Editoriale, 2004.

Mongini, Guido. Ignazio di Loyola: un illuminato al servizio della Chiesa. Milano: 24 Ore Cultura, 2014. OcchetтA, Francesco. Matteo Ricci, il gesuita amato dalla Cina. Elledici, 2009.

Po-Chia-Hsia, Ronnie. Un gesuita nella città proibita. Matteo Ricci (1552-1610). Bologna: Il Mulino, 2012.

Ricai, Matteo. Catechismo. (Il vero significato di "Signore del Cielo" [1603]. Traduzione dal cinese di Antonio Olmi e Giovan Battista Sun. Bologna: Edizioni Studio Domenicano, 2013. . Descrizione della Cina. Macerata: Quodlibet, 2011. 
. Dieci capitoli di un uomo strano - seguito da - Otto canzoni per manicordo occidentale. Macerata: Quodlibet, 2010. Della entrata della Compagnia di Giesù e Christianità nella Cina. Macerata: Quodlibet, 2000.

\section{Referências}

AraúJo, Horácio Peixoto De. Os Jesuítas no Império da China. O Primeiro Século (1582-1680). Lisboa: Instituto Português do Oriente, 2000.

Bartoli, Daniello. Della vita di Sant'Ignazio [1650]. Torino, 1825. 5 voll.

Benedetto xvi. Messaggio del 6 maggio2009 alla Diocesi di Macerata per le celebrazioni ricciane. In: Ceccuca, Piero (Org.). Quarto Centenário da Morte do Padre Matteo Ricci (15521610. Atas do Colóquio Internacional, Florença 10-11 de Maio de 2010. Roma: Società Editrice Dante Alighieri, 2012. p. 16.

Camões, Luís Vaz de. Canto I. In: CAMões, Luís Vaz de. Os Lusíadas. Lisboa: Editora do Instituto de Alta Cultura, 1972. v. 3.

Ceccucar, Piero (org.). Quarto Centenário da Morte do Padre Matteo Ricci (1552-1610) - Macau e o Oriente nas Literaturas de Língua Portuguesa) - Receios e Seduções. Atas do Colóquio Internacional, Florença 10-11 de Maio de 2010. Roma: Societá Dante Alighieri, 2010.

Dreyfus, Paul. Matteo Ricci: uno scienziato alla corte di Pechino. Milano: S. Paolo, 2006. 
Gouvea, António S. I. Ásia Extrema: Primeira Parte - Livros II a VI. Lisboa: Fundação Oriente, 2001.

Lacouture, Jean. Les Jesuites: les conquérants. Paris: Seuil, 1991.

Leite, Serafim Soares. História da Companhia de Jesus no Brasil. 1938. 10 vol.

Mignini, Filippo; Suna, Wang (Org.). Introduzione. In: Ricai, Matteo. Dieci capitoli di un uomo strano, seguito d Otto canzoni per manicordo occidentale. Macerata: Quodlibet, 2010.

Ravasi, Gianfranco. Matteo Ricci e l'inculturazione. In: Ai crinali della storia: Matteo Ricci fra Roma e Pechino. Torino: Allemandi \& C., 2009.

Rica, Matteo. Dell'Amicizia [1595], Macerata: Quodlibet, 2005.

. Lettere (1582-1609). Macerata: Quodlibet, 2001.

Roscioni, Gian Carlo, Il desiderio delle Indie. Storie, sogni e fughe di giovani gesuiti italiani. Torino: Giulio Einaudi Editore, 2001.

Scartezzini, Riccardo. L'innesto della cultura rinascimentale europea in un contesto confuciano. In: Ai crinali della storia, Padre Matteo Ricci fra Roma e Pechino. Torino: Allemandi \& C., 2009.

Valignano, Alessandro, Historia del Principio y Progresso de la Compañia de Jesus en las Indias Orientales (1542-1564). Ed. de Josef Wicki. Roma: Institutum Historicum S.I., 1944. 
Venturi, Pietro Tacchi. Opere storiche del Pe. Matteo Ricci S.I. Macerata: Stab. Tip.Giorgetti, 1911-1913.

Cencucci, Piero. Um testemunho de inéditas modalidades de inculturação ante litteram: a ação missionária dos jesuítas na China da Dinastia Ming nas Cartas do Pe. Matteo Ricci. In: Simas, Monica (Org.). Estudos sobre Macau e outros orientes. São Paulo: Paulistana, 2017. p. 24-52. 